\title{
BMJ Open Cross-sectional study of the association between cataract surgery and age-related macular degeneration in the era of phacoemulsification in the national health and nutrition examination survey 2005-2008
}

\author{
Zhuoting Zhu, ${ }^{1,2}$ Wei Wang (10 , ${ }^{2}$ Huan Liao, ${ }^{3}$ Stuart Keel, ${ }^{4}$ Jian Zhang, ${ }^{2}$ \\ Mingguang $\mathrm{He}$ (1) 1,2,4
}

To cite: Zhu Z, Wang W, Liao H, et al. Cross-sectional study of the association between cataract surgery and agerelated macular degeneration in the era of phacoemulsification in the national health and nutrition examination survey 2005-2008. BMJ Open 2020;10:e032745. doi:10.1136/ bmjopen-2019-032745

- Prepublication history and additional material for this paper are available online. To view these files, please visit the journal online (http://dx.doi. org/10.1136/bmjopen-2019032745).

Received 04 July 2019 Revised 01 November 2019 Accepted 17 December 2019

D) Check for updates

(C) Author(s) (or their employer(s)) 2020. Re-use permitted under CC BY-NC. No commercial re-use. See rights and permissions. Published by BMJ.

For numbered affiliations see end of article.

Correspondence to Professor Mingguang He; mingguanghe@gmail.com

\section{ABSTRACT}

Objective To determine the association between cataract surgery and age-related macular degeneration (AMD) in a representative US sample.

Design Population-based, cross-sectional study.

Setting The US National Health and Nutrition Examination Survey 2005-2008.

Participants A total of 5401 participants aged $\geq 40$ years had information in cataract surgery status and gradable retinal photographs for right eyes.

Methods Cataract surgery status was obtained from questionnaire. Non-mydriatic fundus photographs were collected and AMD status was assessed. The associations between AMD and cataract surgery were evaluated in right eyes using logistic regression models.

Results 0 338 right eyes with any AMD, 107 right eyes (28.9\%) had cataract surgery. After adjusting for multiple variables, there were significant associations between cataract surgery and any AMD (OR 1.36; 95\% Cl 1.03 to 1.81 ) or late AMD (OR 2.48; $95 \% \mathrm{Cl} 1.01$ to 6.09). No significant association was found between cataract surgery and early AMD after adjusting for multiple covariates (OR 1.20; 95\% Cl 0.91 to 1.59).

Conclusion Our results suggest that cataract surgery is associated with the presence of AMD, particularly for late AMD. Longitudinal studies investigating the risk and progression of AMD after cataract surgery are needed in the era of phacoemulsification.

\section{INTRODUCTION}

Cataract and age-related macular degeneration (AMD) are leading causes of visual impairment and blindness in the $\mathrm{USA}^{1}$ and are often presenting concurrently in older persons. ${ }^{2}$ As the population ages, the burden of both age-related conditions is growing.

Cataract surgery is the only cost-effective intervention for improving visual function and quality of life in patients with cataract ${ }^{3}$ and is one of the most commonly performed

\section{Strengths and limitations of this study}

- The present study pooled data from a nationally representative adult sample in the USA.

- Standardised protocol was used for grading agerelated macular degeneration.

- This study controlled for a range of confounding factors.

- Study limitations include the following: (1) the crosssectional nature could not provide the causal relationship, (2) excluded participants tended to be in more disadvantaged socioeconomic status and be unhealthier, (3) cataract surgery was self-reported, (4) no information on the insertion of intraocular lens.

surgeries in the USA. ${ }^{4}$ The presence of AMD is an established risk factor for poor visual outcome following cataract surgery. ${ }^{5}$ Although the introduction of anti-vascular endothelial growth factor (anti-VEGF) has recently revolutionised the management of exudative AMD, ${ }^{67}$ the high price of antiVEGF imposes heavy economic and social burden. Furthermore, there is still no effective treatment for atrophic AMD.

The relationship between cataract surgery and AMD was first identified by a postmortem histopathologic study. ${ }^{8}$ Since then, concerns have been raised about whether cataract surgery increases the incidence and progression of AMD. Despite the extensive studies investigating this relationship, results remain contradictory. ${ }^{9-28}$ Furthermore, surgicalrelated inflammation and light toxicity due to aphakic cataract surgery (postulated mechanisms for the association between cataract surgery and AMD) have decreased 
dramatically in the current era of phacoemulsification. Previous clinical-based prospective results from the agerelated eye disease study (AREDS) and cataract surgery and AMD (CSAMD) study showed no significant relationship between cataract surgery and the risk of AMD. ${ }^{23} 27$ A recent cross-sectional evidence ${ }^{28}$ from a large representative Korean population suggested no significant association between cataract surgery and the presence of AMD, except in left eyes, which was explained as a chance finding. On the contrary, a recent Taiwanese study using population-based claims data documented 1.5-fold increased risk of exudative AMD in those who underwent cataract surgery. ${ }^{19}$

In the light of the rapidly ageing population, irreversible visual impairment and huge social economic burden of AMD, we aimed to elucidate the association between cataract surgery and AMD in a large, nationally representative sample of US middle-aged population.

\section{METHODS}

\section{Study design and population}

Two waves of National Health and Nutrition Examination Survey (NHANES, 2005-2006, 2007-2008) were combined. The NHANES collected health-related information in 2-year patterns and used a complex, multistage, probability sampling methodology to obtain nationally representative surveys of civilian, non-institutionalised US population. The NHANES intentionally oversampled the elderly and ethnicity minority groups. Standard protocols were used across different examination sites.

The research was performed in accordance to the tenets of the Declaration of Helsinki.

\section{Patient and public involvement}

Data used in this analysis were publicly available and deidentified NHANES data. No patient and/or public were involved in the design and conception of our study.

\section{Cataract surgery and AMD status}

Cataract surgery status was obtained from questionnaire. Prior to visual acuity examination, participants were asked the question 'Have you ever had eye surgery to treat cataracts?', and if so, they were further asked 'Which eye(s) had cataract surgery?', which included possible answers of right, left, both or do not know. Individuals who reported history of cataract surgery but did not know which eye(s) were excluded from the current analysis.

In 2005-2008 waves of NHANES survey, non-mydriatic fundus photographs were collected for participants older than 40 years using Canon CR6-45NM Ophthalmic Digital Imaging System and Canon EOS 10D digital camera (Canon USA, One Canon Park, Melville, New York, USA). Photographs were assessed by at least two graders at the University of Wisconsin, Madison according to the modification of the Wisconsin Age-Related Maculopathy Grading Classification Scheme. In brief, early AMD was defined as the presence of drusen and/or pigmentary abnormalities, and late AMD was based on the detection of exudative AMD signs or geographic atrophy.

\section{Covariates}

Demographic characteristics, including age, gender, race, education level, marital status and family income, were collected. Participants were categorised as non-Hispanic white, non-Hispanic black, Mexican American and other ethnicity. Educational level was analysed as a two-level categorical variable: less than high school and completion of or more than high school. Marital status (unmarried and other, married/with a partner) was analysed as a two-level categorical variable. The indicator for family income-the poverty income ratio-was categorised as below poverty $(<1.00)$ and at or above poverty $(\geq 1.00)$. Lifestyle factors included cigarette smoking and alcohol consumption. Former/current smoker was defined as participants who currently smoked and had smoked at least 100 cigarettes in their lifetime. Current drinker was defined as participants who currently drank.

General health was assessed by body mass index (BMI), physical activity, $\mathrm{C}$ reactive protein (CRP) and comorbidities. Height and weight were used to calculate BMI $(\mathrm{kg} /$ $\mathrm{m}^{2}$ ). Obesity was defined as BMI $>30 \mathrm{~kg} / \mathrm{m}^{2}$. The 2008 Physical Activity Guideline for Americans suggests at least 2.5 hours of moderate-intensity or $75 \mathrm{~min}$ of vigorousintensity aerobic physical activity per week or an equivalent combination of moderate-intensity and vigorous-intensity aerobic activity for health benefits. We categorised participants into two groups based on whether the 2008 Physical Activity Guideline was met or not. CRP was categorised as two groups (high CRP level: CRP $\geq 1 \mathrm{mg} / \mathrm{dL}$ or not).

Clinical comorbidities included diabetes mellitus, hypertension, hyperlipidaemia, chronic kidney disease (CKD) and self-reported history of cardiovascular disease (CVD). Diabetes mellitus was defined as serum glycosylated haemoglobin $>6.5 \%,{ }^{29}$ the use of insulin or diabetic tablets or self-reported history of diabetes mellitus. Hypertension was defined as systolic blood pressure of $\geq 140 \mathrm{~mm} \mathrm{Hg}$ or diastolic blood pressure $\geq 90 \mathrm{~mm}$ $\mathrm{Hg}$, the use of antihypertensive agents or self-reported history of hypertension. Hyperlipidaemia was based on total cholesterol $\geq 240 \mathrm{mg} / \mathrm{dL}$, the use of lipid-lowering medications or self-reported history of high cholesterol. CKD was defined as estimated glomerular filtration rate $<60 \mathrm{~mL} / \mathrm{min} / 1.73 \mathrm{~m}^{2}$. Self-reported history of CVD was based on previous diagnosis of congestive heart failure, coronary heart disease, angina, heart attack or stroke.

\section{Statistical analyses}

All statistical analyses were performed using Stata (V.14.0; StataCorp., College Station, Texas, USA). The data set was set up with survey commands in Stata to account for the complex and multistage sampling design of NHANES to generate nationally representative estimates. Characteristics of eyes were reported by using means and SEs for continuous variables and numbers and weighted percentages for categorical variables. We used design-adjusted 
one-way analysis of variance and Rao-Scott Pearson $\chi^{2}$ for the comparison of continuous and categorical variables, respectively. Logistic regression modelling was used to determine the association of cataract surgery with AMD status. Separate analyses were conducted for any, early or late AMD. Unadjusted models were used to estimate ORs and $95 \%$ CIs for each status of AMD, to determine covariates significantly associated with outcomes. Significant covariates $(\mathrm{p}<0.05)$, along with cataract surgery status, were added to models investigating their effects on each status of AMD in multivariable-adjusted logistic regression models. In order to verify the robustness of our results, we also performed sensitivity analysis for left eyes and combing available data from both eyes. Multivariable-adjusted generalised estimating equation (GEE) models were used to account for correlations of paired eyes within the same participant and determine relationships between cataract surgery and AMD status. Two-sided $p$ values $<0.05$ were considered significant for statistical inferences.

\section{RESULTS}

From the 6797 eligible participants aged 40 years and older in 2005-2008 NHANES surveys, 5401 had complete data on cataract surgery status and gradable retinal photographs for right eyes were included in the present analysis. Compared with participants with complete data, participants with incomplete data were more likely to be older, non-Hispanic black, less educated, unmarried, in disadvantaged socioeconomic status, never smoker, abstainer/former drinker and unhealthier regarding physical activity and clinical comorbidities (all $\mathrm{p}<0.05)$. Other characteristics of participants excluded and included are illustrated in online supplemental table 1.

Overall, 566 right eyes $(8.0 \%)$ underwent cataract surgery. Of 338 right eyes with any AMD, 107 right eyes $(28.9 \%)$ underwent cataract surgery. Table 1 provides the characteristics of right eyes. Univariable logistic regression models showed covariates, including age, race, marital status, smoking status, obesity, diabetes mellitus, hypertension, CKD and self-reported CVD, were significantly associated with any AMD and early AMD. There were statistically significant associations between late AMD and age, race, marital status, obesity, hypertension, hyperlipidaemia, CKD or self-reported CVD in the univariable logistic models. These results from logistic regression modelling are outlined in table 2.

After adjusting for significant covariates identified in the univariable logistic regression models, significant associations were observed between cataract surgery and any AMD (OR 1.36; 95\% CI 1.03 to 1.81) or late AMD (OR 2.48; 95\% CI 1.01 to 6.09 ). However, no significant association was found between cataract surgery and early AMD after adjusting for multiple covariates for right eyes. Detailed results are provided in table 3. Similar results were observed when performing sensitivity analysis for
Table 1 Characteristics of participants by right eyes

\begin{tabular}{|c|c|}
\hline Characteristics & $\begin{array}{l}\text { Right eyes } \\
(n=5401)\end{array}$ \\
\hline Age (SE), years & $56.1 \pm 0.39$ \\
\hline Female, number (\%) & $2713(52.9)$ \\
\hline Cataract surgery, number (\%) & $566(8.0)$ \\
\hline Any AMD, number & 338 \\
\hline Age (SE), years & $68.9 \pm 0.88$ \\
\hline Cataract surgery, number (\%) & $107(28.9)$ \\
\hline Early AMD, number & 296 \\
\hline Age (SE), years & $67.6 \pm 0.93$ \\
\hline Cataract surgery, number (\%) & $81(24.6)$ \\
\hline Late AMD, number & 42 \\
\hline Age (SE), years & $78.1 \pm 1.00$ \\
\hline Cataract surgery, number (\%) & $26(60.6)$ \\
\hline
\end{tabular}

All proportions, means and standard errors are weighted estimates of the US population characteristics, taking into account the complex sampling design of the National Health and Nutrition Examination Survey.

AMD, age-related macular degeneration.

left eyes or combining available data from both eyes in GEE models (online supplemental table 2).

\section{DISCUSSION}

In this large nationally representative sample of the US population 40 years and older, our study provided evidence that previous cataract surgery may be associated with AMD, particularly late AMD.

The relationship between cataract surgery and AMD has been intensively investigated through postmortem histopathologic study, cross-sectional study, cohort study, retrospective case-control study and randomised controlled trial, but results have been conflicting. ${ }^{9-28}$ The significant link between cataract surgery and AMD in our study is consistent with previous studies. ${ }^{9-19}$ Dated back to 1989, Liu et al found that cataract surgery without intraocular implantation might place participants at increased risks of AMD using the nationally representative crosssectional study (NHANES-I). After pooling results from three population-based studies, Freeman and colleagues claimed the strong association between cataract surgery and late AMD. ${ }^{11}$ Longitudinal studies, such as the Beaver Dam Eye Study and Blue Mountain Eye Study, documented higher risks of late AMD after cataract surgery. ${ }^{8-10} 121317$ Similarly, cataract surgery was significantly associated with long-term incidence of late AMD in the Rotterdam Eye Study. ${ }^{815}$ Three recent clinical-based case-control studies consistently demonstrated that cataract surgical patients had higher risks of development and progression of AMD with follow-up length ranging from 1 to 5 years. ${ }^{14} 1819$

Our results were contrary to findings from some previously published studies. ${ }^{20-28}$ Population-based 
Table 2 Logistic regression models of risk factor for AMD

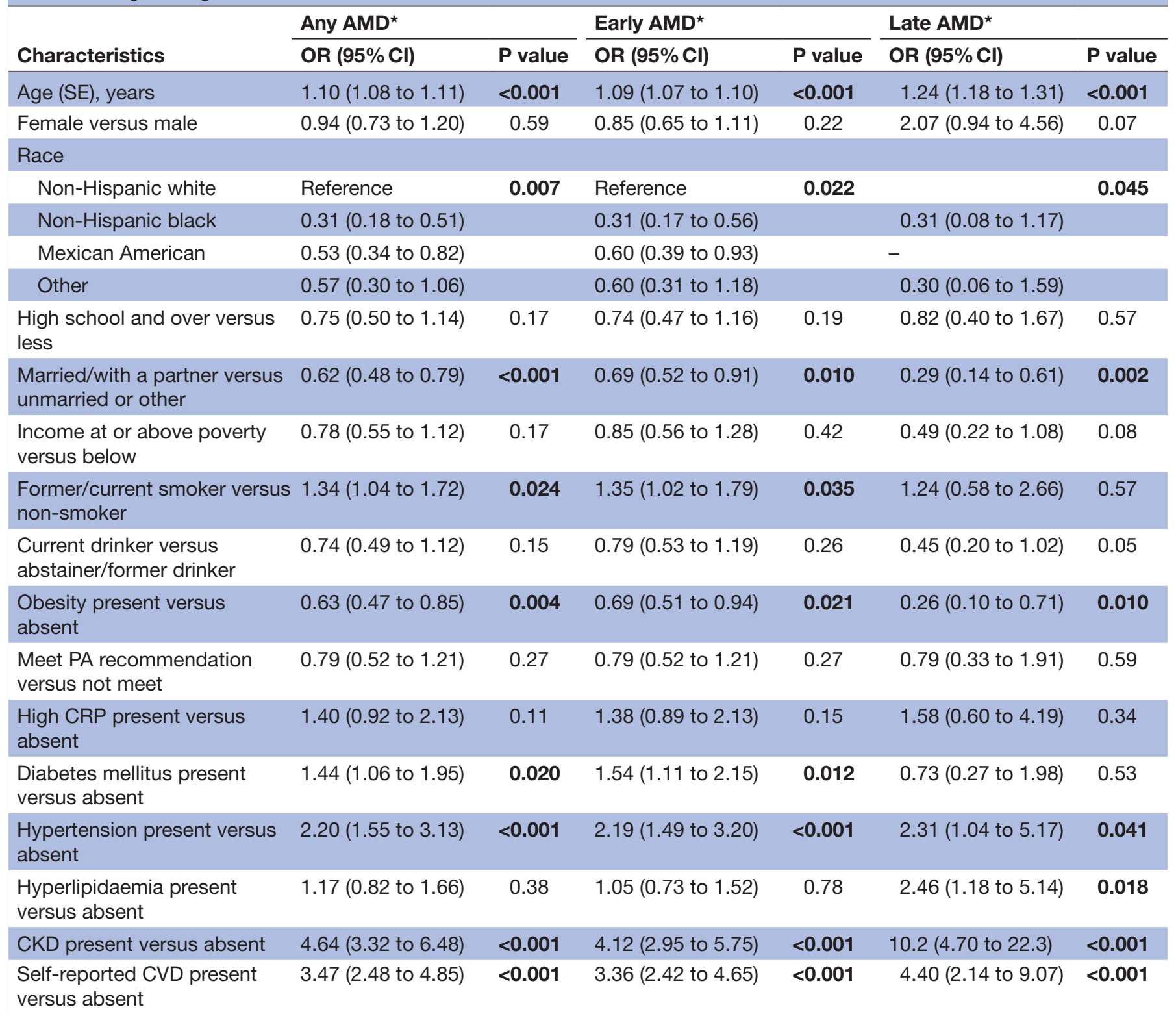

Boldface indicates statistical significance $(P<0.05)$.

${ }^{*}$ Comparisons were between each AMD group and the no AMD group.

AMD, age-related macular degeneration; CKD, chronic kidney disease; CRP, C reactive protein; CVD, cardiovascular disease; PA, physical activity.

cross-sectional results from Visual Impairment Project, ${ }^{20}$ Beijing Eye Study ${ }^{25}$ and Korean NHANES ${ }^{28}$ found no significant association between cataract surgery and AMD. The only randomised controlled trial conducted on this topic suggested clear benefits of phacoemulsification for patients at high risk of AMD progression but without significant evidence for the progression to choroidal neovascularisation. ${ }^{24}$ However, the generalisability of this result might be subject to the small sample size $(n=56)$. The lack of a significant association between cataract surgery and AMD was also documented in clinical-based studies, including a study of Armbrecht $e t$ $a l,{ }^{21}$ a study of Baatz $e t a l^{22}$ and CSAMD. ${ }^{26}{ }^{27}$ The AREDS concluded no significant effect of cataract surgery on the progression of AMD to advanced status. ${ }^{23}$ However, the analysis in the AREDS did find a statistically significant increase in the risk of advanced AMD in eyes with cataract surgery. Of note, many differences, including demographics, age range, sample size, study design, follow-up length, analytic paradigm and confounding factors, exist between our study and earlier studies, which might have led to the discrepancies. Previous studies investigating the association between cataract surgery and AMD are summarised in table 4 .

Several possible explanations for the association between cataract surgery and AMD have been proposed. 
Table 3 Multiple variable adjusted models for AMD and cataract surgery status

\begin{tabular}{|c|c|c|}
\hline \multirow[b]{2}{*}{ AMD type } & \multicolumn{2}{|l|}{ Right eyes } \\
\hline & OR $(95 \% \mathrm{Cl})$ & P value \\
\hline \multicolumn{3}{|l|}{ Any AMD* } \\
\hline Phakia & Reference & \\
\hline Cataract surgery & $1.36(1.03$ to 1.81$)$ & 0.033 \\
\hline \multicolumn{3}{|l|}{ Early AMD* } \\
\hline Phakia & Reference & \\
\hline Cataract surgery & 1.20 (0.91 to 1.59$)$ & 0.18 \\
\hline \multicolumn{3}{|l|}{ Late AMD† } \\
\hline Phakia & Reference & \\
\hline Cataract surgery & 2.48 (1.01 to 6.09$)$ & 0.048 \\
\hline
\end{tabular}

Boldface indicates statistical significance.

*Adjusted for age, gender, race, marital status, smoking status, obesity, diabetes mellitus, hypertension, chronic kidney disease and self-reported cardiovascular disease.

†Adjusted for age, gender, race, marital status, obesity, hypertension, hyperlipidaemia, chronic kidney disease and selfreported cardiovascular disease.

AMD, age-related macular degeneration.

One possibility is the similar underlying mechanism behind cataract and AMD. Previous studies indicated that AMD appeared to be more prevalent in patients with cataract. ${ }^{911} 3031$ Several physiologic or genetic mechanisms underlying lens opacity formation may also play important roles in the pathogenesis of macular degeneration. ${ }^{914}$ Due to the high level of cataract surgical coverage in the USA, the cataract surgery can be regarded as a surrogate of cataract. Alternatively, common risk factors shared by cataract and AMD potentially have effects on their relationship, including older age, smoking status and CVD. ${ }^{32}{ }^{33}$ However, in our study, a comprehensive series of confounders were adjusted in final models and the significant association between cataract surgery and AMD still persisted. Of note, we could not exclude the possibility of incomplete adjustment for important unknown factors, such as genetic factors.

Another proposed explanation for the significant association between cataract surgery and AMD is surgical inflammation. Inflammatory response is common after cataract surgery and may exacerbate the short-term risk of occurrence and progression of AMD. ${ }^{34}$ A retrospective cohort study indicated higher susceptibility to cystoid macular oedema or deterioration of choroidal neovascularisation after cataract surgery among patients with wet AMD. ${ }^{18}$ Therefore, we speculated that cataract surgery might predispose eyes to the development or progression of AMD. Of note, techniques in cataract surgery have been improved greatly and phacoemulsification procedures have sharply reduced inflammatory responses. The significant association between cataract surgery and AMD in the current phacoemulsification era is, to less extent, due to the inflammation caused by cataract surgery. The third possible explanation for the increased risk of AMD after cataract surgery is the greater intensity of UV or short-wavelength light exposure after cataract surgery. ${ }^{35-37}$ Several studies indicated that lens might play a protective effect on retina health. ${ }^{14}$ Aphakic patients had been documented to show more severe macular degeneration than those phakic subjects. ${ }^{9}$ However, the greater likelihood of cataract surgery with implantation of intraocular lenses and advent of UV-blocking or blue light-blocking intraocular lenses had suggested to largely reduce the insult of UV or short-wavelength light on the macular. However, a very recent systemic review concluded that there was still unclear regarding the protective function of blue light-filtering intraocular lenses on macular health or the reduced risk associated with the development or progression of AMD.$^{38}$ Other studies suggested that mechanisms underlying the significant relationship between cataract surgery and AMD could be the intraoperative photic damage caused by the operating microscope ${ }^{39}$ Further research is needed to clarify possible mechanisms underlying the significant association between cataract surgery and AMD, if this significant association is confirmed in other studies.

Our study has several strengths, including the large nationally representative sample size, standardised protocol for grading AMD and availability of comprehensive confounders. Of note, our study was also limited by several points. First, as a cross-sectional study, our study could not provide the causal relationship between cataract surgery and AMD. More research is needed to investigate the longitudinal relationship between cataract surgery and AMD in the era of phacoemulsification. Second, excluded participants tended to be in more disadvantaged socioeconomic status and be unhealthier with respect to lifestyles and clinical comorbidities, which might bias the association between cataract surgery and AMD. Third, the self-reported status of cataract surgery might be subjected to the recall bias. Fourthly, we did not have detailed information on the presence of intraocular lens and/or the type of intraocular lens, therefore, we could not examine the effects of aphakia or different types of intraocular lenses on the status of AMD. However, the aphakic cataract surgery is currently scarce. Last but not the least, we could not exclude the possibilities of chance findings. Further studies are needed to corroborate our results.

In conclusion, in this nationally representative population-based study, we found evidence that cataract surgery was significantly associated with any AMD and late AMD, after adjusting for multiple covariables. This may emphasise the need to thoroughly evaluate the retina prior to cataract surgery and inform the potential risk of AMD to cataract patients when recommending cataract surgery. Furthermore, close retinal follow-up after cataract surgery is recommended, particularly in highrisk individuals. Longitudinal studies investigating the risk and progression of AMD after cataract surgery are needed to confirm this finding. 
Table 4 Summary of previous studies investigating the association between cataract surgery and AMD

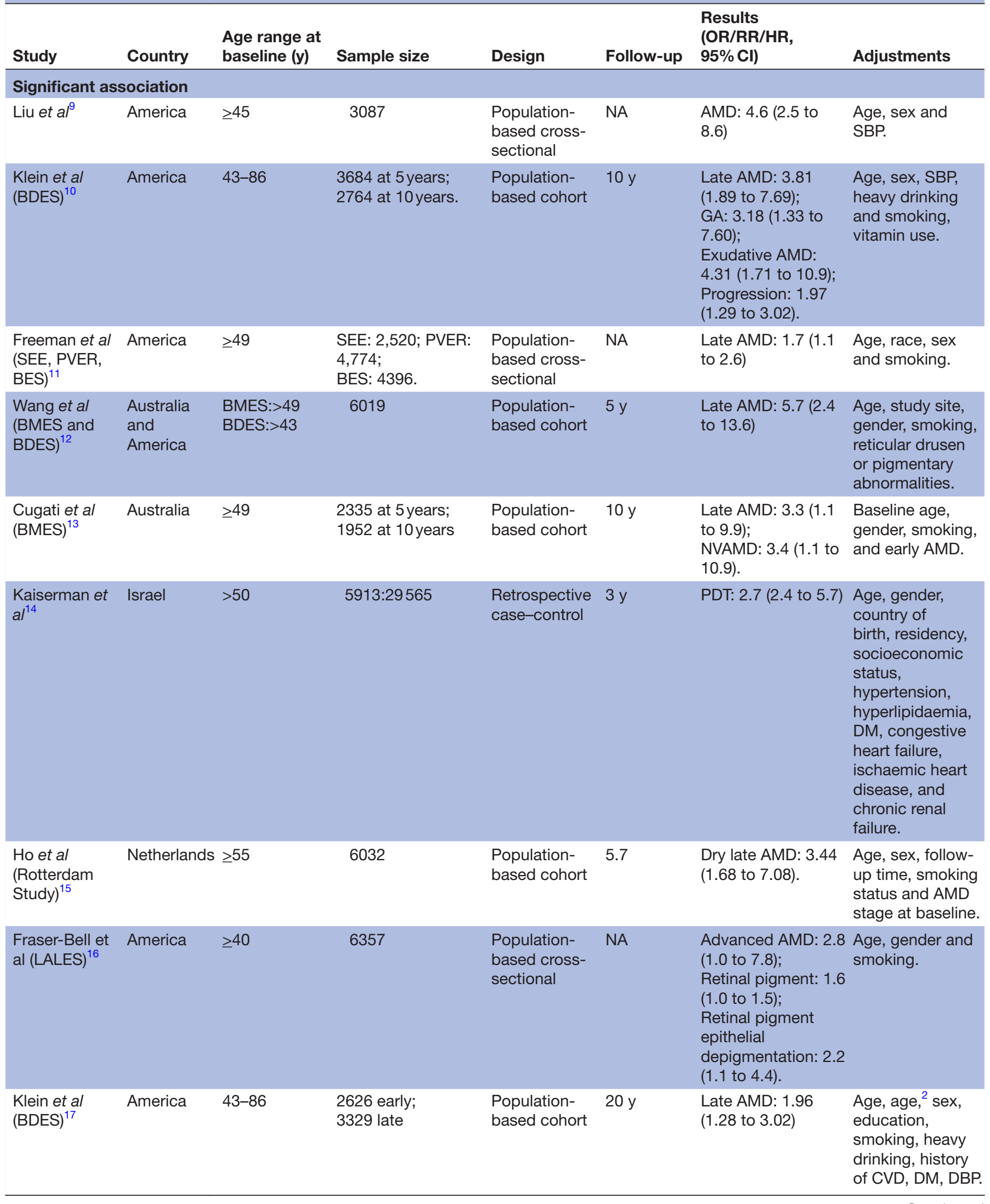


Table 4 Continued

\begin{tabular}{|c|c|c|c|c|c|c|c|}
\hline Study & Country & $\begin{array}{l}\text { Age range at } \\
\text { baseline }(y)\end{array}$ & Sample size & Design & Follow-up & $\begin{array}{l}\text { Results } \\
\text { (OR/RR/HR, } \\
95 \% \mathrm{Cl} \text { ) }\end{array}$ & Adjustments \\
\hline Saraf et $a l^{18}$ & America & $\begin{array}{l}\text { Case: } \\
80.8 \pm 6.5 \\
\text { Control: } \\
79.2 \pm 9.1\end{array}$ & $39: 42$ & $\begin{array}{l}\text { Retrospective } \\
\text { case-control }\end{array}$ & $1 \mathrm{y}$ & $\begin{array}{l}\text { No more injections, } \\
\text { but more } \\
\text { susceptibility to } \\
\text { cystoid macular } \\
\text { oedema or } \\
\text { exacerbation } \\
\text { of choroidal } \\
\text { neovascularisation. }\end{array}$ & NA \\
\hline Ho et $a l^{19}$ & $\begin{array}{l}\text { China, } \\
\text { Taiwan }\end{array}$ & $\geq 49$ & $3465: 10395$ & $\begin{array}{l}\text { Prospective } \\
\text { case-control }\end{array}$ & $5 y$ & $\begin{array}{l}\text { NVAMD: } 2.68 \text { (1.55 } \\
\text { to } 4.66) .\end{array}$ & $\begin{array}{l}\text { Geographical } \\
\text { location, } \\
\text { urbanisation } \\
\text { level, monthly } \\
\text { income, DM, } \\
\text { hypertension, } \\
\text { CVD and } \\
\text { hyperlipidaemia. }\end{array}$ \\
\hline
\end{tabular}

\section{Non-significant association}

\begin{tabular}{|c|c|c|c|c|c|c|c|}
\hline $\begin{array}{l}\text { McCarty et al } \\
(\text { VIP })^{20}\end{array}$ & Australia & $\geq 40$ & 4345 & $\begin{array}{l}\text { Population- } \\
\text { based cross- } \\
\text { sectional }\end{array}$ & NA & $\begin{array}{l}\text { Not significant in } \\
\text { the multivariate } \\
\text { model. }\end{array}$ & $\begin{array}{l}\text { Age, cigarette } \\
\text { smoker, use of } \\
\text { ACE inhibitor, use } \\
\text { of cholesterol- } \\
\text { lowering } \\
\text { medication }\end{array}$ \\
\hline
\end{tabular}

\begin{tabular}{|c|c|c|c|c|c|c|c|}
\hline $\begin{array}{l}\text { Armbrecht et } \\
\left.a\right|^{21}\end{array}$ & Scotland & $\geq 40$ & $40: 43$ & $\begin{array}{l}\text { Prospective } \\
\text { case control }\end{array}$ & $1 y$ & $\begin{array}{l}\text { Only } 2 \% \text { of surgical } \\
\text { eyes progressed to } \\
\text { wet AMD. }\end{array}$ & NA \\
\hline Holger et $a l^{22}$ & Germany & - & 696:202 & $\begin{array}{l}\text { Retrospective } \\
\text { case-control }\end{array}$ & $1 \mathrm{y}$ & $\begin{array}{l}\text { NVAMD: } 1.30 \text { (0.52 } \\
\text { to } 3.24) .\end{array}$ & $\begin{array}{l}\text { Age, baseline } \\
\text { visual acuity. }\end{array}$ \\
\hline $\begin{array}{l}\text { Chew et al } \\
\text { (AREDS) }\end{array}$ & America & $55-80$ & 4577 & Cohort study & $5 y$ & $\begin{array}{l}\text { NVAMD: } 1.08 \text { (0.65 } \\
\text { to } 1.72) ; \\
\text { Central GA: } 0.98 \\
\text { (0.64 to } 1.49) .\end{array}$ & $\begin{array}{l}\text { Baseline age, } \\
\text { gender, race, } \\
\text { history of } \\
\text { smoking. }\end{array}$ \\
\hline Hooper et al ${ }^{24}$ & Australia & $67-92$ & $27: 29$ & $\begin{array}{l}\text { Randomised } \\
\text { controlled trial }\end{array}$ & $6 m$ & $\begin{array}{l}3.7 \% \text { of } \mathrm{CNV} \text { in } \\
\text { surgical group } \\
\text { compared with } \\
\text { none in control } \\
\text { group }(p=1.0) \text {. }\end{array}$ & NA \\
\hline $\begin{array}{l}\text { Xu et al } \\
(B E S)^{25}\end{array}$ & China & $\geq 40$ & 3826 & $\begin{array}{l}\text { Population- } \\
\text { based cross- } \\
\text { sectional }\end{array}$ & NA & $\begin{array}{l}\text { Unilateral surgery } \\
\text { was not associated } \\
\text { with intereye } \\
\text { differences in } \\
\text { presence of early } \\
\text { ( } p=0.99) \text { or late } \\
\text { AMD }(p=0.99) .\end{array}$ & NA \\
\hline $\begin{array}{l}\text { Wang et al } \\
\left(_{(C S A M D)^{26}}\right.\end{array}$ & Australia & $\geq 65$ & 1244 & $\begin{array}{l}\text { Clinic-based } \\
\text { cohort }\end{array}$ & $3 y$ & $\begin{array}{l}\text { Late AMD: } 0.74 \\
\text { (0.23 to } 2.36) ; \\
\text { Early AMD: } 1.07 \\
\text { (0.74 to } 1.65) \text {. }\end{array}$ & $\begin{array}{l}\text { Age, sex, } \\
\text { smoking or early } \\
\text { AMD lesions at } \\
\text { baseline. }\end{array}$ \\
\hline $\begin{array}{l}\text { Wang et al } \\
(\text { CSAMD })^{27}\end{array}$ & Australia & $\geq 65$ & 1057 & $\begin{array}{l}\text { Clinic-based } \\
\text { cohort }\end{array}$ & $4-5 y$ & $\begin{array}{l}\text { Late AMD: } 0.7 \text { (0.4 } \\
\text { to } 1.2) ; \\
\text { Early AMD: } 0.7 \text { (0.5 } \\
\text { to } 1.1) .\end{array}$ & $\begin{array}{l}\text { Age, sex, baseline } \\
\text { AMD status. }\end{array}$ \\
\hline
\end{tabular}

Continued 
Table 4 Continued

\begin{tabular}{|c|c|c|c|c|c|c|c|}
\hline Study & Country & $\begin{array}{l}\text { Age range at } \\
\text { baseline }(y)\end{array}$ & Sample size & Design & Follow-up & $\begin{array}{l}\text { Results } \\
\text { (OR/RR/HR, } \\
95 \% \mathrm{Cl} \text { ) }\end{array}$ & Adjustments \\
\hline Park et $\left.a\right|^{28}$ & Korea & $\geq 40$ & 17987 & $\begin{array}{l}\text { Population- } \\
\text { based cross- } \\
\text { sectional }\end{array}$ & NA & $\begin{array}{l}\text { Any AMD: } 1.02 \\
\text { (0.87 to } 1.21) ; \\
\text { Early AMD: } 0.98 \\
\text { (0.82 to } 1.16) ; \\
\text { Late AMD: } 1.42 \\
\text { (0.88 to } 2.29) \text {. }\end{array}$ & $\begin{array}{l}\text { Age, sex, } \\
\text { smoking } \\
\text { status, income, } \\
\text { education level, } \\
\text { occupation, DM, } \\
\text { dyslipidaemia, } \\
\text { overweight, } \\
\text { hepatitis B } \\
\text { surface antigens } \\
\text { and anaemia. }\end{array}$ \\
\hline
\end{tabular}

AMD, age-related macular degeneration; AREDS, age-related eye disease study; BDES, BeaverDam Eye Study; BES, Baltimore Eye Survey; BES, Beijing Eye Study; BMES, Blue Mountain Eye Study; CNV, choroidal neovascularisation; CSAMD, cataract surgery and age-related macular degeneration; CVD, cardiovascular disease; DBP, diastolic blood pressure; DM, diabetes mellitus; GA, graphic atrophy; LALES, Los Angeles Latino Eye Study; NA, not available; NVAMD, neurovascular age-related macular degeneration; PDT, photodynamic therapy; PVER, Proyecto VER; RR, risk ratio; SBP, systolic blood pressure; SEE, Salisbury eye evaluation; VIP, visual impairment project.

\section{Author affiliations}

${ }^{1}$ Guangdong Eye Institute, Department of Ophthalmology, Guangdong Provincial People's Hospital, Guangdong Academy of Medical Sciences, Guangzhou, China ${ }^{2}$ State Key Laboratory of Ophthalmology, Zhongshan Ophthalmic Center, Sun Yatsen University, Guangzhou, China

${ }^{3}$ Neural Regeneration Group, Institute of Reconstructive Neurobiology, University of Bonn, Bonn, Germany

${ }^{4}$ Centre for Eye Research, Melbourne University, East Melbourne, Victoria, Australia

Contributors Study concept and design: ZZ, MH. Acquisition, analysis or interpretation: all authors. Drafting of the manuscript: ZZ, WW and HL. Critical revision of the manuscript for important intellectual content: WW, SK and MH. Statistical analysis: ZZ, WW and JZ. Obtained funding: MH. Administrative, technical or material support: ZZ, WW, SK, JZ and MH. Study supervision: MH.

Funding present work was supported by Fundamental Research Funds of the State Key Laboratory in Ophthalmology. Professor Mingguang He receives support from the University of Melbourne at Research Accelerator Program and the CERA Foundation. The Centre for Eye Research Australia receives Operational Infrastructure Support from the Victorian State Government. The sponsor or funding organization had no role in the design or conduct of this research.

Competing interests None declared.

Patient consent for publication Not required.

Ethics approval The NHANES protocols were approved by the National Center for Health Statistics research ethics review board and informed consents were obtained from all participants.

Provenance and peer review Not commissioned; externally peer reviewed.

Data availability statement All data relevant to the study are included in the article or uploaded as supplementary information.

Supplemental material This content has been supplied by the author(s). It has not been vetted by BMJ Publishing Group Limited (BMJ) and may not have been peer-reviewed. Any opinions or recommendations discussed are solely those of the author(s) and are not endorsed by BMJ. BMJ disclaims all liability and responsibility arising from any reliance placed on the content. Where the content includes any translated material, BMJ does not warrant the accuracy and reliability of the translations (including but not limited to local regulations, clinical guidelines, terminology, drug names and drug dosages), and is not responsible for any error and/or omissions arising from translation and adaptation or otherwise.

Open access This is an open access article distributed in accordance with the Creative Commons Attribution Non Commercial (CC BY-NC 4.0) license, which permits others to distribute, remix, adapt, build upon this work non-commercially, and license their derivative works on different terms, provided the original work is properly cited, appropriate credit is given, any changes made indicated, and the use is non-commercial. See: http://creativecommons.org/licenses/by-nc/4.0/.

\section{ORCID iDs}

Wei Wang http://orcid.org/0000-0002-5273-3332

Mingguang He http://orcid.org/0000-0002-6912-2810

\section{REFERENCES}

1 Congdon N, O'Colmain B, Klaver CCW, et al. Causes and prevalence of visual impairment among adults in the United States. Arch Ophthalmol 2004;122:477-85.

2 Qian CX, Young LH. The impact of cataract surgery on AMD development and progression. Semin Ophthalmol 2014;29:301-11.

3 Kobelt G, Lundström M, Stenevi U. Cost-Effectiveness of cataract surgery. method to assess cost-effectiveness using registry data. $J$ Cataract Refract Surg 2002;28:1742-9.

4 Schein OD, Cassard SD, Tielsch JM, et al. Cataract surgery among Medicare beneficiaries. Ophthalmic Epidemiol 2012;19:257-64.

5 Forooghian F, Agrón E, Clemons TE, et al. Visual acuity outcomes after cataract surgery in patients with age-related macular degeneration: age-related eye disease study report No. 27. Ophthalmology 2009;116:2093-100.

6 Rosenfeld PJ, Brown DM, Heier JS, et al. Ranibizumab for neovascular age-related macular degeneration. $N$ Engl J Med 2006;355:1419-31.

7 Bhisitkul RB, Desai SJ, Boyer DS, et al. Fellow Eye Comparisons for 7-Year Outcomes in Ranibizumab-Treated AMD Subjects from ANCHOR, MARINA, and HORIZON (SEVEN-UP Study). Ophthalmology 2016;123:1269-77

8 van der Schaft TL, Mooy CM, de Bruijn WC, et al. Increased prevalence of disciform macular degeneration after cataract extraction with implantation of an intraocular lens. $\mathrm{Br} \mathrm{J}$ Ophthalmol 1994;78:441-5

9 Liu IY, White L, LaCroix AZ. The association of age-related macular degeneration and lens opacities in the aged. Am J Public Health 1989;79:765-9.

10 Klein R, Klein BEK, Wong TY, et al. The association of cataract and cataract surgery with the long-term incidence of age-related maculopathy: the Beaver dam eye study. Arch Ophthalmol 2002;120:1551-8.

11 Freeman EE, Munoz B, West SK, et al. Is there an association between cataract surgery and age-related macular degeneration? data from three population-based studies. Am J Ophthalmol 2003;135:849-56.

12 Wang JJ, Klein R, Smith W, et al. Cataract surgery and the 5year incidence of late-stage age-related maculopathy: pooled findings from the Beaver dam and blue Mountains eye studies. Ophthalmology 2003;110:1960-7. 
13 Cugati S, Mitchell P, Rochtchina E, et al. Cataract surgery and the 10-year incidence of age-related maculopathy: the blue Mountains eye study. Ophthalmology 2006;113:2020-5.

14 Kaiserman I, Kaiserman N, Elhayany A, et al. Cataract surgery is associated with a higher rate of photodynamic therapy for agerelated macular degeneration. Ophthalmology 2007;114:278-82.

15 Ho L, Boekhoorn SS, et al. Cataract surgery and the risk of aging macula disorder: the Rotterdam study. Invest Ophthalmol Vis Sci 2008;49:4795-800.

16 Fraser-Bell S, Choudhury F, Klein R, et al. Ocular risk factors for agerelated macular degeneration: the Los Angeles Latino eye study. Am J Ophthalmol 2010;149:735-40.

17 Klein BEK, Howard KP, Lee KE, et al. The relationship of cataract and cataract extraction to age-related macular degeneration: the Beaver dam eye study. Ophthalmology 2012;119:1628-33.

18 Saraf SS, Ryu CL, Ober MD. The effects of cataract surgery on patients with wet macular degeneration. Am J Ophthalmol 2015;160:e481:487-92.

19 Ho J-D, Xirasagar S, Kao L-T, et al. Neovascular age-related macular degeneration is associated with cataract surgery. Acta Ophthalmol 2018;96:e213-7.

20 McCarty CA, Mukesh BN, Fu CL, et al. Risk factors for age-related maculopathy: the visual impairment project. Arch Ophthalmol 2001;119:1455-62.

21 Armbrecht AM, Findlay C, Kaushal S, et al. Is cataract surgery justified in patients with age related macular degeneration? A visual function and quality of life assessment. $\mathrm{Br} \mathrm{J}$ Ophthalmol 2000;84:1343-8.

22 Baatz H, Darawsha R, Ackermann H, et al. Phacoemulsification does not induce neovascular age-related macular degeneration. Invest Ophthalmol Vis Sci 2008;49:1079-83.

23 Chew EY, Sperduto RD, Milton RC, et al. Risk of advanced agerelated macular degeneration after cataract surgery in the agerelated eye disease study: AREDS report 25. Ophthalmology 2009;116:297-303.

24 Casparis H, Lindsley K, Kuo IC, et al. Surgery for cataracts in people with age-related macular degeneration. Cochrane Database Syst Rev 2012;6:CD006757.

$25 \mathrm{Xu}$ L, You QS, Cui T, et al. Association between asymmetry in cataract and asymmetry in age-related macular degeneration. The Beijing eye study. Graefes Arch Clin Exp Ophthalmol 2011;249:981-5.

26 Wang JJ, Fong CS-U, Rochtchina E, et al. Risk of age-related macular degeneration 3 years after cataract surgery: paired eye comparisons. Ophthalmology 2012;119:2298-303.
27 Wang JJ, Fong CS-U, Burlutsky G, et al. Risk of age-related macular degeneration 4 to 5 years after cataract surgery. Ophthalmology 2016;123:e1821:1829-30.

28 Park SJ, Lee JH, Ahn S, et al. Cataract surgery and age-related macular degeneration in the 2008-2012 Korea National health and nutrition examination survey. JAMA Ophthalmol 2016;134:621-6.

29 World Health Organization. Use of glycated haemoglobin (Hba1c) in the diagnosis of diabetes mellitus: abbreviated report of a WHO consultation, 2011. Available: http://www.who.int/diabetes/ publications/report-hba1c_2011.pdf [Accessed 1 Dec 2013].

30 Buch $\mathrm{H}$, Vinding $\mathrm{T}$, la Cour $\mathrm{M}$, et al. Risk factors for age-related maculopathy in a 14-year follow-up study: the Copenhagen City eye study. Acta Ophthalmol Scand 2005;83:409-18.

31 Krishnaiah S, Das T, Nirmalan PK, et al. Risk factors for agerelated macular degeneration: findings from the Andhra Pradesh eye disease study in South India. Invest Ophthalmol Vis Sci 2005;46:4442-9.

32 Tabandeh H, Chaudhry NA, Boyer DS, et al. Outcomes of cataract surgery in patients with neovascular age-related macular degeneration in the era of anti-vascular endothelial growth factor therapy. J Cataract Refract Surg 2012;38:677-82.

$33 \mathrm{Hu} \mathrm{C}-\mathrm{C}$, Lin H-C, Sheu J-J, et al. Neovascular age-related macular degeneration is not associated with coronary heart disease in a Chinese population: a population-based study. Acta Ophthalmol 2017;95:e587-91.

34 Donoso LA, Kim D, Frost A, et al. The role of inflammation in the pathogenesis of age-related macular degeneration. Surv Ophthalmol 2006;51:137-52.

35 Dillon J, Zheng L, Merriam JC, et al. Transmission of light to the aging human retina: possible implications for age related macular degeneration. Exp Eye Res 2004;79:753-9.

36 Holz FG, Bellman C, Staudt S, et al. Fundus autofluorescence and development of geographic atrophy in age-related macular degeneration. Invest Ophthalmol Vis Sci 2001;42:1051-6.

37 Sparrow JR, Nakanishi K, Parish CA. The lipofuscin fluorophore A2E mediates blue light-induced damage to retinal pigmented epithelial cells. Invest Ophthalmol Vis Sci 2000;41:1981-9.

38 Downie LE, Busija L, Keller PR. Blue-Light filtering intraocular lenses (IOLs) for protecting macular health. Cochrane Database Syst Rev 2018;5:CD011977.

39 Libre PE. Intraoperative light toxicity: a possible explanation for the association between cataract surgery and age-related macular degeneration. Am J Ophthalmol 2003;136:961. 